\title{
Dossiê História do Esporte
}

Organizadores: André Mendes Capraro e Miguel Archanjo de Freitas Jr. 


\title{
PROCESSO CIVILIZADOR E TRANSFORMAÇÕES SOCIAIS: UMA ANÁLISE DAS TEORIAS ELISIANAS EM RELAÇÃO ÀS CIÊNCIAS SOCIAIS DO ESPORTE ${ }^{1}$
}

\author{
Proces de Civilisation et Transfomations Sociales: Une Analyse de La \\ Theorie Eliasienne Au Regard des Sciences Sociales du Sport
}

Jean-François Loudcher ${ }^{2}$

\begin{abstract}
RESUMO
A teoria da civilização proposta por Norbert Elias ainda é bastante atual, como evidenciado pelas inúmeras referências ao autor nos campos da história e da sociologia. Seu arcabouço teórico seria, portanto, dotado de uma certa eficiência. No entanto, existem muitas críticas, em particular no campo das ciências sociais do esporte, um lugar de reflexão bastante privilegiado para o sociólogo alemão a partir da década de 1960. Portanto, sua teoria deve ser aplicada nessa área ou não? A questão é ambígua. De fato, o esporte não é realmente o objeto de estudo de Norbert Elias, sendo, na maioria das vezes, um elemento para apoiar a demonstração do seu modelo teórico. Contudo, o conceito de esportivização que o autor desenvolveu é geralmente reduzido a um simples processo de competição e institucionalização, enquanto o fenômeno da evolução do esporte trata-se de algo muito mais complexo. Atividades tão diversas como ginástica, esporte profissional, práticas de saúde e/ou de lazer não podem inscrever-se diretamente num enquadramento teórico do processo civilizatório. A análise sócio-histórica é, portanto, necessária para alterar o esquema elisiano, para que não apenas as reflexões que dele surjam não sejam deslocadas, mas que também possam iluminar o campo das ciências sociais.
\end{abstract}

Palavras-chave: Norbert Elias, Violência, Esporte, Processo Civilizador, Integração social.

\section{RÉSUMÉ}

La théorie du procès de civilisation de Norbert Elias est toujours d'actualité comme en témoignent les multiples références à l'auteur que ce soit en histoire ou en sociologie. Son cadre théorique serait donc doté d'une certaine efficacité. Pour autant, les critiques sont multiples, notamment, dans le domaine des sciences sociales du sport, champ de réflexion assez privilégié du sociologue allemand à partir des années 1960. Dès lors, est-ce sa théorie qu'il faut incriminer ou bien son application dans ce domaine? La question est ambigüe. En effet, le sport n'est pas réellement l'objet d'étude de Norbert Elias, mais, le plus souvent, un élément pour étayer sa démonstration. Or, la

1 Texto com tradução do original em francês realizada pelo Prof. Dr. Marcelo Moraes e Silva (UFPR/Brasil) com revisão técnica do Prof. Dr. André Mendes Capraro (UFPR/Brasil) e Profa. Dra. Evelise Amgarten Quitzau (UDELAR/Uruguai).

2 Professeur des universités en sciences historiques et sociales à l'Université de Bordeaux. Il est actuellement co-responsable du master management du sport à Bordeaux. E-mail: jean-francois.loudcher@u-bordeaux.fr. ORCID: http://orcid.org/00000002-8536-9602. 
notion de sportivisation qu'il élabore est réduite généralement à un procédé simple de compétition et d'institutionnalisation alors que le phénomène d'évolution du sport est beaucoup plus complexe. Des activités aussi diverses que la gymnastique, le sport professionnel, les pratiques de santé et/ou de loisir ne peuvent pas directement s'inscrire à la suite de cette théorie du processus de civilisation. L'analyse sociohistorique s'avère alors nécessaire pour amender le shéma éliasien afin que, non seulement les réflexions qui en découlent ne soient pas mal posées, mais qu'elles puissent aussi éclairer le champ des sciences sociales.

Mots-clefs: Norbert Elias, Violence, Sport, Processus de civilisation, Intégration sociale.

\section{Introdução}

Embora seja bastante evidente que Norbert Elias teve e ainda tem uma influência notável sobre os intelectuais franceses, tal presença é muito variável ao longo do tempo, variando de acordo com cada campo de estudo. Assim, embora Raymond Aron, desde 1939, conhecesse o autor e sua obra (Elias; 1973; 1974; 1975), foi necessário esperar até os anos 1970-1980 para que o pensamento do intelectual alemão, conforme indica Roger Chartier (2010), começasse a se espalhar entre os historiadores da Idade Clássica. Por sua vez, Nathalie Heinich (1997) e Marc Joly (2012) apontam que os sociólogos franceses descobriram a obra de Norbert Elias somente no final do século XX. Obviamente, a divulgação dos trabalhos do sociólogo alemão é fortemente ligada à diversidade de temas abordados pelo problema do controle da violência no âmbito de um processo civilizador (ELIAS, 1973) e que pode abrir-se para interpretações transversais que misturam aspectos culturais, políticos e sociais de diversas naturezas. Poder-seia, portanto, esperar cruzamentos entre esses campos de estudo. Além disso, o próprio Norbert Elias (1991) não insiste que os sociólogos tenham uma cultura histórica? Entretanto, além das respectivas reflexões realizadas por historiadores e sociólogos (com pouca presença da antropologia) relacionadas à validade da teoria elisiana, o ponto de vista histórico que solicita o cruzamento de perspectivas é pouco desenvolvido na França, apesar do questionamento de Roger Chartier, que desenvolveu uma posição plural em relação ao intelectual alemão.

No entanto, talvez seja uma das especificidades do campo das ciências sociais do esporte suscitar fortemente essas abordagens transversais. A apresentação dos trabalhos do sociólogo alemão por ocasião da publicação de seu primeiro artigo sobre esporte na revista dirigida por Pierre Bourdieu (ELIAS, 1976) mobilizou imediatamente pesquisadores como Jacques Defrance (1976) e Georges Vigarello. Este último, após um primeiro encontro com Norbert Elias, escreveu um importante artigo em conjunto com Roger Chartier sobre as "trajetórias do esporte" (CHARTIER; VIGARELLO, 1982). A posterior publicação, em 1994, da tradução francesa de seu livro seminal, escrito com Eric Dunning, deu a visibilidade definitiva ao seu trabalho nesse campo (ELIAS; DUNNING, 1984). Desde então, o legado do sociólogo alemão tem sido objeto de várias reflexões destinadas a "repensar" sua abordagem (BODIN; ROBÈNE ,2016).

Nesse sentido, torna-se ainda mais legítimo que acadêmicos especializados no campo das ciências sociais do esporte se interessem pelo pensamento de Norbert Elias, pois esse 
tópico apresenta uma parte significativa de seu trabalho, provavelmente por permitir uma rastreabilidade relativamente fácil do objeto ao longo de vários séculos. Além disso, a evolução do esporte parece responder bastante bem ao esquema do processo civilizador desenvolvido pelo autor. Assim, a ideia de capturar o exercício da violência legítima por parte do Estado nas civilizações ocidentais seria perfeitamente ilustrada pelo fenômeno da transformação do esporte em torno do estabelecimento de meios de regulação cada vez mais estritos. No entanto, o "esporte" que, de acordo com a leitura acadêmica mais difundida, apareceu na Inglaterra do século XVII-XVIII, seria comparável ao que se espalhou um século depois ou, ainda mais, ao que se globalizou na década de 1960 -1970? Ou, indo além disso, os processos que regem sua expansão são da mesma natureza?

Em resumo, a atração inicial pela abordagem elisiana que explica o surgimento do esporte passa a deixar espaço para críticas à luz dos novos dados (históricos e sociais) que ocorreram nos últimos anos. Bastante raros, nos anos 1970-1980, os trabalhos foram enriquecidos com produções em francês (LOUDCHER; VIVIER; GOUNOT, 2001; VIVIER; LOUDCHER, VIEILLE-MARCHISET, 2015) e em línguas anglo-saxônicas (EICHBERG, 1974; MANDELL, 1976; GUTTMANN, 1978), bem como com a tradução para a língua francesa de certos autores de referência, como Allen Guttmann (LOUDCHER, 2008). Portanto, se essa discussão levanta a crítica à aplicação uniforme de um determinado esquema elisiano nas ciências sociais do esporte, consequentemente, parece lógico que ele possa gerar reservas sobre a utilização da própria teoria. Sendo assim, o objetivo central do presente artigo é utilizar o campo do esporte para discutir os fundamentos teóricos da teoria do processo civilizador.

\section{Os fundamentos da teoria de Norbert Elias: um olhar sobre sua utilização nas ciências sociais do esporte}

\section{Uma rápida evocação}

Norbert Elias oferece uma interpretação da história ocidental que se baseia na observação de um aumento na expressão de pudor e na repressão da violência desde a Idade Média. Esse conjunto de procedimentos complexos contribui para a formação de um processo civilizador. Como tal, toda uma série de processos projetados para controlar comportamentos foi implementada, associando funções biológicas, como a defecação, a bebida, o sexo, até a violência, a uma função social através de tabus e de considerações vergonhosas e culpadas, bem como sentimentos de ansiedade e vergonha. O resultado foi uma diferenciação das funções sociais e o surgimento de novas restrições psíquicas que, através da internalização das emoções, permitiram maior controle das atitudes, principalmente daquelas realizadas em público. Esses comportamentos passam a ser rejeitados nos "bastidores", conforme indica Dunning (1999), configurando "um limiar de repugnância". Esse processo civilizador reflete uma interação específica entre o grupo e as pessoas, permitindo entender a emergência do conceito de indivíduo no contexto do desenvolvimento do Estado em sua forma moderna. Este 
último monopoliza legitimamente a violência, graças a dois procedimentos, um na forma da cobrança de impostos e o outro relativo à curialização dos cavaleiros (subjugação da corte). Nas palavras de Dunning (1999, p.44): “O que está em jogo é a transição gradual, através da luta competitiva, de sociedades feudais altamente descentralizadas para estados dinásticos altamente centralizados e, eventualmente, para estados-nação".

No entanto, como essa "dinâmica do ocidente" (ELIAS, 1975) está diretamente ligada à história de cada país, especialmente às organizações estatais e sociais que podem variar em sua forma e duração, a expressão do controle "legítimo" da violência se realiza de maneira diferente. Pode ser tanto o resultado de um estado ditatorial quanto o resultado de reações "brutais" de nações democráticas que veem sua autoridade sendo diluída. O processo civilizador não faz parte de uma linearidade impecável na redução da violência. Uma certa flexibilidade é possível no grau e na natureza do controle que diferencia ou amortece reações excessivamente violentas através do que Norbert Elias chamou de a "the triad of basic controls" (tríade de controles básicos), isto é, “(...) o controle de seres humanos sobre eventos extra-humanos naturais, o controle do povo sobre todos e o controle de cada indivíduo sobre si mesmo" (ELIAS, 1978, p.156). Assim, a dimensão "política", tomada em seu sentido mais amplo de controle social e estatal é fundamental para a compreensão da teoria elisiana. Ela é particularmente solicitada no lento mecanismo de codificação universal experimentada por certas práticas físicas codificadas e institucionalizadas.

Por fim, embora a reflexão teórica de Norbert Elias seja discutida algumas vezes, em particular no que diz respeito à nudez corporal, que seria menos difundida do que ele sugere (DUERR, 1998), ela não é fundamentalmente questionada. Além disso, o estudo do esporte foi uma via privilegiada de análise para o sociólogo alemão, que viu em seu trabalho, por meio dos fenômenos de eufemização da violência processos particularmente interessantes que alimentaram seu argumento.

\section{Modelagem sócio-política e esportiva}

Mais precisamente, foi através do estudo do advento de uma categoria específica de práticas físicas, os passatempos, que Norbert Elias fortaleceu as bases de sua interpretação sobre o processo civilizador. Na obra "Sociedade de Corte" (ELIAS, 1974), o autor descreveu como o movimento de pacificação das elites esteve enraizado nos processos geopolíticos que ocorreram na idade clássica. A reunificação de lotes comunitários díspares em terras produtivas pertencentes a grandes proprietários (enclosures) seria um dos fenômenos cruciais dessas transformações. É verdade que esse fenômeno, embora bastante difundido na Europa (POUSSOU, 2014), desenvolveu-se mais cedo e sistematicamente na Inglaterra, devido ao seu regime político (Monarquia Constitucional) e à sua insularidade. Os camponeses ingleses, despojados dessas terras comunais que lhes permitiam subsistir, tornaram-se economicamente mais independentes em relação aos grandes proprietários, uma vez que precisam procurar outros meios de subsistência.

Um fenômeno inverso ocorreu na França, onde, de acordo com Norbert Elias, foi estabelecida uma relação um pouco menos livre entre nobres e pequenos camponeses. Consequentemente, os campesinos ingleses dariam um significado muito particular às terras 
comunais porque elas concediam a possibilidade de se reunir para brincar e se divertir. Assim, em 1728, os moradores de Great Tey (Essex) ganharam o julgamento contra o Landlord que queria arar o campo para semear enquanto o espaço era usado para a tradicional fogueira de 5 de novembro e como um local de prática do futebol (BRAILSFORD, 1999). Essa organização geopolítica induziu formas bastante diferentes de práticas corporais entre os dois países, principalmente no destino do folk-football (LOUDCHER, 2019), o que pode explicar, em parte, a gênese de certos esportes, como, por exemplo, o rúgbi e o futebol.

Nesta teorização, Norbert Elias destacou um mecanismo que Montesquieu, em 1748, já havia descrito como a teoria do poder e do contrapoder, onde um equilibrava o outro. Porém, o autor alemão foi além ao observar que os desafios existentes entre os dois principais partidos políticos da época estavam moldando outros relacionamentos bem mais complexos. Se a alta aristocracia (Whigs) era bastante católica, mas também tinha em seu seio um pequeno grupo protestante que era proprietária de terras, por outro lado, os conservadores (Tories), representados principalmente por uma burguesia enriquecida e católica, possuíam terras, mas tinha uma parte protestante que era relativamente carente (FAURE; SUAUD, 2015). Essa configuração evidencia que o capital fundiário, mas também a crença religiosa, estavam no centro de interesses comuns que levariam essas duas frações a se entenderem, afinal estavam sob a ameaça de ver suas propriedades diminuírem e/ou desaparecerem, revivendo as lutas que levaram à decapitação do rei Carlos I (1649) e à "Gloriosa Revolução" (1688). Esse consenso foi expresso na constituição inglesa por assimilação a um ideal antigo que defendia "um equilíbrio de poder" (COTTRET, 1996) entre o rei, os senhores e os comuns. Existiu, portanto, um aumento da estabilidade política na Inglaterra, apesar de alguns acontecimentos violentos terem ocorrido na Irlanda e na África do Sul. Nesse contexto, a gentry (pequena aristocracia e pequena/grande burguesia) e os Lords passaram a dispor de tempo e dinheiro, o que lhes dava a possibilidade, durante os séculos XVII e XVIII, de patrocinar e praticar esses passatempos. Várias atividades foram organizadas por estes grupos em torno da paixão pelas apostas (WIGGLESWORTH, 1996) e envolviam principalmente corridas de cavalos ou a pé, bem como críquete, boliche ou boxe.

Este esquema é fundamental para entender a teorização de Norbert Elias, pois o autor posiciona o esporte como um elemento original do processo civilizador. Em particular, o sociólogo alemão postulava uma homologia entre essa formação bipartidária incutida nas elites políticas e a estrutura básica dos passatempos que levariam ao esporte moderno. Esse fenômeno de transformação dos divertimentos foi denominado pelo autor como esportivização. No entanto, ele pode resumir sozinho dois séculos de evolução das práticas físicas ocidentais nesse campo?

\section{Repensando o conceito de esportivização: a natureza do Esporte Moderno em questão}




\title{
Uma noção bastante vaga
}

Em 1976, em seu primeiro artigo publicado em francês sobre esporte, Norbert Elias especificou como era sua abordagem nesse campo. O autor definiu o conceito de esportivização, supostamente para reescrever a trajetória do esporte como um elemento integrante do processo civilizador:

\begin{abstract}
O termo "esporte" refere-se a jogos competitivos e exercícios físicos de todas as sociedades, bem como ao tipo específico de jogos competitivos que apareceram com a palavra na Inglaterra. Com relação a esse processo - que poderíamos chamar de esportivização dos jogos competitivos se a palavra não soasse tão ruim - é preciso se perguntar se é possível encontrar a recente evolução da estrutura e da organização das atividades de lazer que chamamos de tendências esportivas, tão únicas quanto as que caracterizam a estrutura e organização do trabalho no processo de industrialização (ELIAS, 1976, p.2-21).
\end{abstract}

Contudo, a noção ainda permanece bastante vaga. A definição engloba o tema do jogo e da competição, bem como as atividades de lazer. No entanto, é muito claro que os exercícios físicos que mais interessavam ao autor eram aqueles que evoluíam de acordo com uma "estrutura" que supunha regras, códigos, etc., e que fizeram parte de uma organização de trabalho muito própria do fenômeno da industrialização. Em suma, a visão "moderna" de um esporte competitivo, determinada por um órgão centralizado semelhante a uma federação, resume muito bem seu propósito. O autor evocava a ideia de um esporte que surgia desde a sua criação na Inglaterra sem considerar uma ruptura: "Como explicar que uma forma inglesa de passatempo chamado de esporte serviu de modelo, principalmente nos séculos XIX e XX, para o desenvolvimento de atividades de lazer em escala mundial?" (ELIAS, 1976, p. 2-21).

No entanto, essa temporalidade e o papel desses divertimentos estão longe de ser óbvios. É verdade que o século XVIII viu uma expansão significativa das práticas físicas "organizadas" que visavam aspectos lúdicos e/ou lazer. As regras do boxe e as do Cockfightings (brigas de galo) foram publicadas em 1743 e as do golfe e do críquete em 1744. Mas como essas prescrições diferem em sua natureza daquelas estabelecidas na antiguidade, durante torneios de cavaleiros ou no decorrer das competições de tiro com arco e flecha? Na realidade, mais do que as regras por si só, existia o desejo de impor uma certa padronização que tinha o intuito de regular as apostas que haviam se espalhado fortemente naquela sociedade. Se certos indivíduos se distinguem em sua edificação como no boxe (Broughton), na maioria das vezes foram organizações privadas como o Jockey Club (1750-1751), o Royal and Ancient Club, com o golfe (WIGGLESWORTH, 1996) ou Hambledon Club (1767) com o críquete (FORD, 1972) que promoveram as apostas. Um convívio de classe se desenvolveu em torno das apostas, levando, em meados do século XVIII, a uma intervenção legislativa que estabeleceu um mínimo de 50 libras para poder apostar ${ }^{3}$. Esse esquema parece responder à reflexão elisiana do controle centralizado, embora não à do controle estatal, ao contrário do que aconteceu na França no mesmo período. O movimento, apesar de tudo, se generalizava se "democratizando", na

3 Devem-se essas referências e informações a Wray Vamplew (2017). 
medida em que diferentes classes sociais criavam seus clubes sem que houvesse uma "mistura" cultural.

De qualquer forma, esse fenômeno é deslocado no tempo do período de parlamentarização do poder inglês, que ocorreu, segundo Norbert Elias, pelo menos um século antes. Consequentemente, não é exatamente no século XIX que se pode falar do esporte moderno?

\section{Profissionalismo e amadorismo: em direção ao "esporte moderno"}

O movimento de "gentrificação" ocorrido durante o "take-off" (PERKIN, 2002) da revolução industrial (1782-1810), bem como a evolução "democrática" que se seguiu, são muitas vezes consideradas as causas da explicação do fenômeno de esportivização. No entanto, o conceito de passatempos refere-se a formas muito diversas e que são difíceis de reduzir a esse processo. Os membros da nobreza podiam apostar em práticas como o boxe, críquete e corridas, porém as classes sociais mais baixas também participaram, em certa medida, desses divertimentos. Se, por um lado, eles não se contentavam mais em "regular" esses passatempos, como no críquete ou na corrida, por outro, a natureza das apostas havia mudado: elas não consistiam mais em altas somas de dinheiro, tornando-se mais numerosas e de valores mais baixos (BRAILSFORD, 1999). Assim, o desenvolvimento dessas práticas necessitou da intervenção de pessoal qualificado, que passou a ganhar cada vez mais importância e que não eram mais recrutados apenas pelos nobres.

Nesse contexto, profissionais e amadores começavam a se distinguir. Enquanto os primeiros passavam a se preocupar com um treinamento mais meticuloso e com uma dieta rigorosa, os outros seguiam todo um conjunto de códigos morais que não eram restritos a algumas regras destinadas a organizar as partidas e as apostas (DAY; CARPENTER, 2015). Finalmente, a tese usual de aculturação da classe alta (tese marxista desenvolvida por Norbert Elias e retomada por Pierre Bourdieu em 1984) é posta em questão. Afinal, a invenção e o desenvolvimento de passatempos no século XVIII também foi resultado da ação de classes mais populares. Além disso, John Goulstone (2000), ao analisar a criação do rúgbi, defendeu a ideia de que o folk-football havia tornado possível "socializar" os jovens estudantes do liceu, tomando emprestado as regras em vigor nos clubes e associações. É certo que essas Public schools frequentemente recuperaram práticas que vinham sendo desenvolvidas há muito tempo em outros espaços sociais. Por exemplo, na Trinity College em Dublin, uma forma de "futebol" já era praticada regularmente desde 1811, muito antes das regras do rúgbi serem publicadas em 1845. De maneira geral, o "futebol-rúgbi" foi estruturado antes do seu reconhecimento "oficial" pelas escolas públicas britânicas (WEST, 1991; COLLINS, 2015). Mais especificamente, as diferenças de jogo com o pé e com a mão estavam sendo estabelecidas, principalmente sob a influência das regras emitidas pelo Rochdale Club em 1841 (GOULSTONE, 1986). Em outras palavras, pode-se dizer que a prática desses esportes rurais (STONEHENGE, 1875; CORBIN, 1995) ocorreu em grande parte entre 1800 a 1840 (CHANDLER, 1991), com ou sem a ajuda de seus Headmasters (diretores), que não haviam mostrado interesse em praticá-los. Samuel Butler, Headmaster de Shrewsbury de 1796 a 1838, não viu nenhum apelo educacional no folk-football. Afinal o jogo era “(...) feito para açougueiros ... mais adaptado para meninos de 
fazendas e lavradores do que para jovens cavalheiros" (DUNNING; SHEARD, 2005). Quanto a Thomas Arnold, seu verdadeiro impacto é muito questionável desde que ele deixou o Rugby em 1842.

Na realidade, esses estabelecimentos de ensino somente transformaram as práticas já existentes. Elas tinham outra natureza? De qualquer forma, as escolas acrescentaram uma dimensão crucial a esse movimento ao impor uma abordagem de distinção social elitista que levou ao desenvolvimento da ética amadora. Rugby era uma das sete Public Schools cuja missão era a de formar a elite da nação, mas que haviam sido criadas originalmente para receber principalmente estudantes de classe média e/ou das menos favorecidas. A gentrificação que se operou na sociedade inglesa levou as classes dominantes a enviar seus filhos para tais estabelecimentos de ensino com o intuito de se distinguirem. O resultado foi uma relação desequilibrada entre Headmasters, de classes sociais médias, e seus alunos. Enquanto os professores se impunham por seu domínio do grego e do latim, a alta burguesia passava a valorizar um treinamento para uma "independência viril" (DUNNING; SHEARD, 2005), que era algo muito diferente do ensino usual e requereria um repensar pedagógico. Ao desenvolver o Prefect-fagging (DUNNING, 1999) (a regra pela qual o mestre poderia prevalecer na medida em que os direitos dos mais antigos - Prefects - poderiam ser exercidos em atividades extracurriculares), o método encontrou uma exitosa aplicação nos esportes, como ilustrado na vida colegial de Tom Brown em 1857, na Rugby. Portanto, a prática de esportes rurais foi gradualmente aceita e, além disso, desenvolvida e aprimorada pelos Headmasters. Uma necessidade educacional acabou se afirmando como fundamental em sua existência. Além disso, foi acompanhado por um simbolismo distintivo de classe, do qual faz parte a lenda do jovem William Webb Ellis de 1823. Neste processo de "invenção da tradição" (HOBSBWAN; RANGER, 2012), a ideologia do amadorismo se espalhou utilizando-se da cultura do Fair Play, bem como do desempenho emitido pelas classes de notários e pela nobreza elitista.

No entanto, o processo de pacificação das elites inglesas no século XVIII, descrito por Norbert Elias, não foi suficiente para explicar a dinâmica de distinção e fragmentação que estava se espalhando na sociedade inglesa. A vida era "dura e cruel" (BRAILSFORD, 1999), e mesmo as regulações sociopolíticas ocorreriam gradualmente desde o estabelecimento do habeas corpus (1679). Foi somente no início do século XIX que outros regulamentos se estenderam na maneira de administrar a população. O objetivo era o de reduzir violência para tornar mais legítimo o seu uso por órgãos de controle e repressão.

Cabe destacar que este desenvolvimento estava ocorrendo mais ou menos da mesma forma em toda a Europa ${ }^{4}$. Se o "esporte" elitista inglês - na sua versão amadora - podia ser entendido como uma maneira de controlar uma certa fração da população, não é preciso dizer que as reformas educacionais que atravessam toda a Europa também faziam parte desse processo, mas que se exprimiram de maneiras bastante distintas. Os filantropinum alemães e suíços de Basedow, as ideias educacionais rousseaunianas, os planos revolucionários de educação ou a ginástica pestalozziana de Amoros na França foram, de alguma forma, a contrapartida da prática inglesa denominada esporte. No entanto, será que esses processos não se influenciaram mutuamente para dar outra forma ao esporte no início do século XX?

4 Problema levantado por Michel Foucault (1975), relacionado ao controle populacional. 


\section{Limite epistemológico elisiano sobre o conceito de esporte}

De qualquer forma, a definição de esporte moderno permanece confusa na obra de Norbert Elias. Isso ocorre pelo fato de o autor não ter levado em conta todas as práticas e influências acima mencionadas. O sociólogo alemão não analisou as mudanças que a Inglaterra experimentava na segunda metade do século XVIII, não evidenciando como os passatempos, esportes ingleses e esportes modernos se diferiram entre si no século seguinte. Certamente, Norbert Elias argumentou sobre a evolução das práticas gregas antigas e medievais (ELIAS; DUNNING, 1986), para justificar a utilização do conceito de Estado-nação no fenômeno de transformação do esporte. No entanto, como esse não era seu objetivo, o autor acabou não especificando seu impacto na maneira como as federações "democráticas" do século XIX foram criadas e/ou na forma como o esporte se desenvolveu no cenário internacional. Afinal, o contexto estava mudando radicalmente! Enquanto o papel dos ingleses se tornava cada vez menos predominante, o dos franceses (Coubertin, Guérin, Reichel, Rousseau...), americanos e alemães somente aumentavam.

A posição da Inglaterra foi muito relativa no desenvolvimento do esporte moderno no século XIX, visto que havia um envolvimento cada vez mais globalizado por parte das sociedades ocidentais. Isso enfatiza o pensamento de um fenômeno que se mostra muito complexo e que um termo tão vago quanto o de esportivização não pode abranger. Existem muitas práticas físicas originais na Inglaterra georgiana ou sob a Regência, porém os diferentes estágios ou inflexões observados requerem interpretações diferenciadas relacionadas às condições de emergência e transformação das práticas físicas, tanto em termos sociopolíticos, como também nas esferas econômica, tecnológica e cultural.

Mas, como pode-se culpar Norbert Elias por não ter contemplado esses trabalhos quando nenhum quadro de análise teórica poderia, e ainda não pode, explicar o fenômeno da aparição do "esporte moderno", visto que sua natureza é complexa de lidar devido às várias mudanças que lhe atravessaram ao longo de vários séculos? Além disso, essas reflexões raramente são mencionadas do ponto de vista acadêmico, sem dúvida à luz da dificuldade teórica acima mencionada. Contudo, tudo transcorre como se o debate estivesse encerrado e o problema tivesse sido "resolvido" há muito tempo. Assim, os "clássicos" historiadores ingleses do esporte, como Richard Holt (1989), Neil Wigglesworth (1996) e Dennis Brailsford (1999), interpretam o surgimento do esporte moderno, concentrando-se principalmente em dados empíricos para explicar fatos mais gerais (sociais, políticos, culturais, etc.). No lado francês, Pierre Arnaud (1995) e Thierry Terret (2016) ampararam-se em uma conceituação "mínima", não produzindo um poderoso quadro teórico. Finalmente, poucos historiadores tentam teorizar sobre o esporte, e foram os sociólogos que se aventuraram com mais frequência na tarefa. No entanto, muitas vezes eles realizaram a empreitada sem acessar materiais empíricos.

Além disso, uma ambiguidade adicional na busca de uma definição de esporte referese ao fato de que a noção de modernidade para historiadores e sociólogos não se refere ao mesmo período histórico. Se, para sociólogos como Ulrich Beck (2001) ou Joseph Maguire (2006), a modernidade surgiu no final do século XVIII, para os historiadores o fenômeno remonta ao Renascimento. Como, então, o esporte moderno pode ser transformado em um "índice de modernidade", fornecendo um instrumento teórico válido? A dinâmica histórica é mal compreendida e alimenta algumas confusões. No entanto, a rápida análise evocada anteriormente mostrou a diversidade de momentos na "invenção" do "esporte moderno". 
Contudo, eles não apenas são pouco considerados, como também não são relacionados.

$\mathrm{Na}$ realidade, existem duas hipóteses que geralmente atraem a atenção de um ponto de vista histórico. A primeira é aquela defendida por acadêmicos como Allen Guttmann (1978) e Jacques Ulmann (1965), que mencionam a aparição do esporte moderno no século XVIII, relacionando-o com a noção de record, um critério que era bastante novo naquele período. Mas a falta de análise deste termo levou a uma confusão (LOUDCHER, 2008). Se, por um lado, o record é frequentemente confundido com a noção de performance, conforme análise realizada pela filósofa Isabelle Quéval (2004), por outro, a comparação envolvendo a mensuração entre duas pessoas semelhantes por meio de categorias é frequentemente ignorada. No entanto, essa última dimensão é essencial, conforme proposto por Richard D. Mandell para quem o registro seria uma estatística geralmente reconhecida, indicando a natureza única do desempenho atlético e de um sexo estabelecido (GUTTMMAN, 1982). Um recorde mundial só pode ser estabelecido se for colocado em contato com outros indivíduos comparáveis (elites, homens, mulheres, crianças...) e que compitam em condições padronizadas. Além disso, o conceito está pouco relacionado - se é que tem alguma relação -, com a especificidade sociopolítica do país ou de uma comunidade, conforme apontado por Norbert Elias através do conceito de configuração. No entanto, se a parlamentarização foi a característica da Inglaterra no século XVIII, ele não pode explicar o período de expansão do "esporte" no século seguinte, especialmente no cenário internacional. De fato, a nação havia se tornado a Grã-Bretanha, onde países como a Irlanda foram integrados, impondo-se como um império mundial conquistador e hegemônico, exceto no que diz respeito ao esporte.

Uma segunda hipótese é então requisitada para tentar explicar o que estava ocorrendo durante o século XIX. Pesquisadores como Henning Eichberg (1997) e Alain Ehrenberg (2004) se apoiam em justificativas econômicas e políticas, bem como no papel das representações nacionais (estado-nação), na tentativa de explicar o surgimento do esporte moderno no período. Os autores apontam a necessidade de uma atividade que se instaurasse à imagem das democracias de massa então em desenvolvimento. Mas como explicar a esportivização mais tardia de certos países, como Alemanha, Itália e Espanha, ou o fato de que alguns esportes modernos se desenvolveram fora desse período (handebol, vôlei, artes marciais, surf...)? Em suma, a especificidade inglesa dos passatempos do século XVIII pode ser questionada em relação à evolução ocidental que coloca em jogo fontes específicas de democratização em massa no século seguinte, permitindo a expansão do esporte moderno, ou seja, falta uma reflexão mais fundamentada para explicar essa "evolução".

De qualquer forma, a homologia estabelecida entre um modelo de prática esportiva mais "moderna" e uma estrutura sociopolítica democrática parece responder ao que se desenvolveu na França durante a segunda metade do século XIX. De fato, o esporte inglês era bastante "fragmentado" e difundiu-se à imagem da sua sociedade civil. Em 1891, em Linton, foram organizadas reuniões para "vendedores", "agricultores", "trabalhadores" e "amadores". A criação de organismos unificadores nacionais associativos e democráticos para impor uma única prática, como na França, não era uma necessidade. No contexto francês, o "discurso republicano" centralizador que estava se espalhando era aquele pelo qual devia-se, ao mesmo tempo, educar o povo sem negligenciar os mais fracos (o solidarismo e o higienismo de Léon Bourgeois; o paternalismo de Frédéric Leplay), enquanto desenvolvia-se também a excelência. Coubertin fará disso o seu cavalo de batalha enquanto cultivava a ambiguidade! Mas como objetivos tão diversos, como solidariedade e ajuda mútua, podem ser combinados com intentos 
antagônicos como o de competição? O ecletismo das práticas físicas (ginástica militar e médica, esportes ingleses, práticas tradicionais) tornou possível promover as diferentes facetas desse discurso estabelecidas pela instalação de uma democracia média (ROSANVALLON, 2000) razoavelmente centralizada. No entanto, esse tipo de "governança" foi aquilo que beneficiou a expansão do esporte em nível internacional, como mostram os trabalhos de Cronin e Holt (2003) e Loudcher e Monnin (2013).

Consequentemente, o caráter mais geral do conceito de esportivização não pode responder a essas diferenças territoriais, nem às evoluções ocorridas no plano social, cultural, político e histórico em torno de um período tão longo. A articulação de diferentes influências (saber/poder, política/cultura/social/econômica) torna-se necessária para "pensar" essa evolução do "esporte" entre os séculos XVIII e XX e, com isso, poder fazer uma teoria coerente. Evidentemente, nem Norbert Elias nem seus detratores nem os atuais pensadores de outras localidades as executaram, embora algumas pistas estejam começando a ser discernidas.

Diante dessa dificuldade, uma interpretação "molle" (mole) da emergência do esporte moderno se espalhou. Tal explicação pode ser resumida em duas etapas e obteve certo sucesso, devido ao fato de que não se opõe ao que foi proposto por Norbert Elias e nem oferece uma ferramenta conceitual interessante. Pierre Arnaud, por exemplo, ao se referir ao sociólogo alemão, indagou que as origens inglesas do esporte ocorrem no século XVIII, acrescentando posteriormente que o fenômeno se espalhou a partir da extensão das "colônias" inglesas durante o século XIX (ARNAUD; RIORDAN, 1998). Da mesma maneira, Georges Vigarello (2000) primeiro advogou a favor do século XVIII, retomando o argumento destinado a mostrar como o uso maciço do metro, das gramas e dos segundos seriam os responsáveis por esta transformação. Então, o autor se inclina para uma evolução decisiva no século XIX, no que diz respeito, por um lado, ao "princípio democrático" que estava se espalhando, embora Vigarello o coloque em perspectiva relativa ao observar que o esporte foi desenvolvido por classes sociais frequentemente elitistas e, por outro lado, pela influência de fenômenos de "institucionalização" e "hierarquia" (VIGARELLO, 2004).

No entanto, o problema de teorizar a emergência do esporte moderno com suas diferentes contradições ainda permanece. Qual é o objeto realmente a ser estudado? São as práticas físicas com suas inflexões, inovações técnicas e tecnológicas, condições sociais (sociais, culturais, políticas) ou as motivações dos indivíduos (emoções, prazer, religiões) que permitiram essas evoluções? Além disso, como essas categorias podem ser articuladas?

\title{
A utilização do pensamento elisiano no campo das ciências sociais do esporte
}

\author{
Entre os "fatores explicativos" e os "a explicar": uma confusão recorrente no \\ campo das ciências sociais do esporte
}


A falta de teorização relativa à emergência do esporte moderno advém, em parte, da dificuldade em identificar o objeto estudado, não permitindo o acompanhamento de seu desenvolvimento histórico. Dessa forma, o recurso à noção de esportivização é uma ferramenta prática que pode evitar muitos questionamentos.

Na sociologia do esporte, alguns autores se referiram a Norbert Elias com mais facilidade, visto que sua obra é a priori compatível com a abordagem bourdieusiana, considerada, então, dominante nessa área na década de 1980. No entanto, uma diferença essencial parece separar Pierre Bourdieu e Norbert Elias, conforme evocado por Jean-Hughes Déchaux (1993, p. 364385):

Os dois autores, portanto, se opõem à questão da historicidade e usam o conceito de habitus para diferentes propósitos: variável explicativa em P. Bourdieu, variável a ser explicada em N. Elias. Em suma, por trás da mesma concepção relacional e estrutural do social, duas teorias de ação substancialmente diferentes são afirmadas.

No entanto, é preciso qualificar melhor essa questão no campo do esporte. De fato, a análise de Norbert Elias sobre o desenvolvimento de passatempos no século XVIII, em conexão com a parlamentarização, recebeu o status de uma variável explicativa, pois ofereceu um modelo para entender a redução da violência a partir do diagrama da configuração de uma partida de futebol. Portanto, pode-se supor que, mesmo em Norbert Elias, essa distinção não é tão consciente. No entanto, essa falta de discernimento entre esses dois pontos de vista é a origem de várias confusões sociológicas e históricas no campo das ciências sociais do esporte. Além disso, a ambiguidade do conceito de esportivização favorece essa amálgama entre as duas opções teóricas. De um lado, baseia-se na condição de existência do esporte moderno (variável explicativa) e, por outro, aquilo que é consequência do fenômeno da modernidade (variável a explicar). Certamente, ambas categorias são interessantes de se operar teoricamente, contudo, torna-se preciso pelo menos distinguir as condições de sua utilização.

Pierre Parlebas (2002), apoiando-se em Norbert Elias, considera como o modelo mais adequado aquele que se refere à visão competitiva e institucional do esporte, ou seja, o das federações e clubes da década de 1960. Contudo, a abordagem é problemática do ponto de vista sócio-histórico. Afinal, pode-se dizer que o esporte moderno não existia antes da criação dos órgãos nacionais de referência? Jogar futebol em 1862, um ano antes da criação da FA, retiraria a prática da modernidade esportiva? De fato, essa definição coloca o problema de cabeça para baixo, pois, em geral, são os praticantes que dão à luz a federação ou os clubes, e não o contrário. Nessas condições, a evolução do esporte é explicada por essa institucionalização, enquanto empiricamente é o oposto que parece funcionar. No entanto, analisando como os indivíduos participaram da criação da FIFA, a simples história institucional se mostra obsoleta. $\mathrm{O}$ foco deve ser tanto nos elementos que vão nessa direção quanto naqueles que a abrandaram, visto que a definição institucional torna epistemologicamente impossível analisar as questões e os debates que levaram ao surgimento do esporte moderno, uma vez que acontecer "antes" não é considerado outra "história possível"5 em relação ao seu propósito.

5 Em referência à história das possibilidades. Mais detalhes em Quentin Deluermoz e Pierre Singaravélou (2016). 
Portanto, a adoção da noção de esportivização permite seu amalgamento com o fenômeno de emergência do esporte moderno, confirmando assim a natureza histórica de um modelo "burguês" vinculado ao desenvolvimento industrial, relação que the foi concedida desde o início. De fato, a lógica da reificação alimenta todo um discurso sobre integração através do esporte que é mais facilmente nutrido por aquele realizado pela esportivização. Ao desenvolver e responder ao esquema eliasiano, o esporte se "civiliza", torna-se menos violento, provando, portanto, que o esporte se "integra". Mas isso não é misturar a variável explicativa com aquela a se explicar? A confusão é sutil e nem sempre é evocada.

\title{
Precisar a noção de "configuração"
}

Certamente, pode-se legitimamente duvidar de uma influência da sociologia americana na obra de Norbert Elias (Franz Boas, Ruth Benedict), pois na sua abordagem a noção de configuração tem um aspecto flutuante:

\begin{abstract}
N. Elias oscila constantemente entre duas visões, "estrutural" e "interacionista" da sociedade. A configuração é apresentada ora como uma estrutura de luta entre grupos ou indivíduos situados hierarquicamente, ora como um jogo cujos efeitos escapam ao cálculo dos atores. É bem possível que o social seja ambos ao mesmo tempo, mas tanto num caso como no outro, a visão é apenas tocada, deixando muitos problemas sem resposta (DÉCHAUX, 1995, p.293-313)
\end{abstract}

No entanto, Norbert Elias parece precisar esse conceito com o estudo do esporte, segundo afirma André Ducret (2011). Em particular, na longa introdução de seu livro publicado em 1994 com Eric Dunning, o sociólogo alemão sugere que: "A partir da posição de partida uma configuração fluida formada pelas duas equipes evolui. Todos os indivíduos estão lá e ficam até o fim, mais ou menos interdependentes; eles se deslocam e se reagrupam um em relação ao outro" (ELIAS; DUNNING, 1994, p.264).

Ainda que André Ducret (2011) note que o papel do árbitro, assim como o dos juízes de linha ${ }^{6}$, essenciais para a partida de futebol, é raramente mencionado, o autor argumenta que essa noção, vista em termos de "dinâmica de jogo", se abriria para uma sociologia real das configurações. Sendo assim, deve ser dado “(...) um novo significado ao se centrar, não nas interações observáveis no seio de cada equipe, mas nas interdependências de todos os jogadores em relação um ao outro, na medida em que juntos formam uma única configuração em tensão" (DUCRET, 2011, p. 8). Em outras palavras, este autor adere a uma análise semiológica das possibilidades de comunicação que Pierre Parlebas (2002) já havia realizado em formas matemáticas extremamente avançadas (gráficos, diagramas e teorias de jogos). Consequentemente, identificar os elementos interdependentes que podem qualificar uma configuração volta, sem dúvida, em parte a uma concepção “(...) cujas linhas principais são

6 NT: No original juges de touche. Termo em francês que se refere ao arbitro assistente, popularmente chamado no Brasil de bandeirinha 
encontradas na teoria de campos de P. Bourdieu" (DÉCHAUX, 1993, p. 293-313). Assim, relações mais ou menos caracterizáveis entre jogadores, em função de sua disposição, terreno e momento, etc., seriam elementos reveladores das posições sociais, culturais, simbólicas e econômicas dos indivíduos em relação às práticas esportivas, um pouco da maneira como realizou Christian Pociello (1995).

Mas essa interpretação da configuração não é a única que pode ser feita sob um olhar elisiano. Notadamente, as relações de interdependência se inscrevem em um determinado contexto. Antes de o jogo com as mãos ter sido proibido em 1863, era evidente que as relações entre jogadores de futebol eram diferentes e respondiam a uma organização sócio-culturalpolítica bastante específica. Além disso, até o início do século XX, na França, a confusão reinava no que se refere ao modo de jogar o esporte. De maneira mais ampla, as formas de jogo variavam de acordo com os locais de prática, como o futebol do " bas d'immeuble" (TRAVERT, 1997). Outras regras estavam relacionadas a um contexto específico da comunidade, e quase todas as formas dessas práticas correspondiam a "modelos de configuração" (ELIAS; SCOTSON, 1997). Parece que essa noção, tal como Norbert Elias a estabeleceu a partir da partida de futebol, não integra suficientemente essa dimensão sociopolítica que ele, no entanto, investigou para compreender o processo de pacificação social das elites no século XVIII. Ora, essa relação é essencial! Afinal, ela permite entender como as configurações podem ser uma fonte de ambiguidade se mantiver apenas as interdependências comunicacionais do jogo de futebol e se forem esquecidos os aspectos sociopolíticos. Consequentemente, essa falta de perspectiva crítica pode levar a aproximações no campo das ciências sociais do esporte. Este é particularmente o caso quando uma certa sociologia das configurações tenta aplicar esse esquema à história do esporte.

Joseph Maguire (2006) generaliza essa reflexão estabelecendo uma periodização dividida em cinco fases. No entanto, esse padrão é muito questionável. Um primeiro limite diz respeito à noção de configuração que Norbert Elias estabeleceu a partir da partida de futebol. De fato, o críquete, que supõe colocações dissimétricas entre as equipes, ou a caça à lebre, por sua "anarquia organizada", oferecem uma forma de configuração incompatível com a definição proposta (COLINS, 2005; VAMPLEW, 2007). O segundo diz respeito à discutível temporalidade que Joseph Maguire evoca. Pode-se endereçar as mesmas críticas sobre as duas primeiras fases que ele empresta de Norbert Elias. A terceira etapa, que ele nomeia de pré-modernização, vai da segunda metade do século XIX à década de 1920, respondendo à institucionalização do atletismo, futebol, rúgbi e tênis, não é tão desprovida de questionamento. De fato, não se sabe sobre quais bases o autor construiu essa categoria (noção de instituição), pois é difícil dizer, por exemplo, como essas federações ou ligas são diferentes daquelas criadas na década de 1950, como as do judô ou da luta livre na França. Além disso, o autor afirma que os ingleses eram "os jogadores dominantes" (MAGUIRE, 2006) quando, no final do século XIX perderam sua supremacia no críquete, rúgbi e futebol (LOUDCHER, 2007). Além disso, seu lugar foi pequeno no movimento olímpico. Coubertin não foi o principal inovador? Enfim, eles não foram os iniciadores de movimentos esportivos internacionais, como futebol (não participaram da FIFA em 1904), boxe (LOUDCHER; DAY, 2013), ginástica, esgrima ou luta. De maneira semelhante, a quarta fase, que vai até os anos 1960, é discutível, pois se caracteriza

7 Uma forma de praticar o futebol típico de bairros populares. 
pela dominação esportiva ocidental. O autor não diz nada sobre as diferenças entre os países, notadamente, no contexto da Guerra Fria. Os esportes evoluíram de maneira diferente e foi preciso esperar, por exemplo, o período entre as duas guerras, para que a Alemanha ou a Itália se esportivizassem, enquanto a França e a Suíça já haviam iniciado esse processo há mais de vinte anos. Finalmente, a quinta fase da mundialização, na qual o poder esportivo ocidental é posto em questão, não é teoricamente sustentada.

Em suma, essa sociologia das configurações repousa em uma análise descritiva muito orientada. Além disso, o empreendimento de "suavização conceitual" das diferentes fases tende a negar os múltiplos contraexemplos para manter apenas a forma reificada de um esporte prédefinido. No entanto, refletir o campo do esporte nesses termos, no sentido de uma verdadeira sociologia, como mencionado acima, supõe levar em conta essa multiplicidade cultural e social de práticas em relação a uma organização sociopolítica específica (HARVEY, 2006). E, é claro, de acordo com os períodos e lugares, essas configurações são pouco compatíveis com um pensamento tão generalizador. Sem dúvida, a falta de trabalhos substanciais, bem como reflexões suficientemente maduras sobre o nível conceitual do assunto, facilitou a afirmação dessa "coerência" global e descritiva: avançar no caminho de uma interpretação teórica para fins explicativos seria um trabalho muito mais ambicioso.

Finalmente, essa sociologia das configurações contribui para difundir a ideia de uma progressão inevitável dos exercícios físicos em direção a um determinado objetivo: o atual esporte competitivo internacional. Tal posição pode surpreender os autores que afirmam ser elisianos (DUNNING; MAGUIRE, 1995). De fato, o sociólogo alemão estava bem ciente do perigo de uma interpretação determinista quando argumentava que outras "formas" esportivas poderiam ter aparecido e que sua modernidade não era uma conclusão inevitável, nem uma finalidade inscrita com antecedência. Mas é verdade, como lembra Roger Chartier (2010), que seu evolucionismo mudou fortemente no final de sua carreira.

Diante dessa visão teórica um tanto rígida, talvez seja necessário devolver à noção de configuração todo o seu dinamismo e seu poder de explicação sociopolítico. Torna-se importante sublinhar o aspecto evolutivo das práticas. Repensar o papel e o lugar das federações e dos órgãos reguladores significa levar em consideração cada esporte e seus diferentes atores. De fato, não apenas as ligas agem de maneira diferente segundo sua natureza (federações amadoras e/ou olímpicas), como também outras formas de regulação se sucedem. Os jornais, por exemplo, tiveram um papel muito importante no início do século XX (LOUDCHER, 2007), enquanto, na década de 1960, o estado francês se engajou massivamente com o esporte. Mais recentemente, os pay-per-view no caso das Mixed Martial Arts condicionaram consideravelmente a evolução da modalidade. Além disso, as práticas esportivas de lazer (esportes de rua e ao ar livre) e saúde (fitness) supõem outras redes relacionais e políticas (autoridades locais, grupos informais de pessoas devido às redes sociais) que não se enquadram nas "tradicionais" federações. Essa diversificação da regulação do campo esportivo, variando de novas práticas conhecidas como "californianas" a sua hibridação através da profissionalização, coloca o "esporte moderno" no centro de uma rede de configurações de difícil identificação. No mínimo, é preciso relativizar o lugar do esporte moderno em seu papel de regulação no conjunto de todo o campo das práticas físicas. No entanto, o esporte competitivo moderno é visto como o produto dominante e de referência ao qual as práticas físicas se relacionam (DEFRANCE, 1995). Nesse sentido, ao menos é necessário adotar uma postura mais global e um pouco mais matizada.

Na realidade, pensar o esporte moderno em relação a um "estado" final é reforçado pela 
confusão entre a variável "explicativa" e "a ser explicada". Mais ainda, é necessário distinguir as práticas corporais que se desenvolvem independentemente de qualquer lógica federativa daquelas que possuem uma elaboração histórica de acordo com organizações sociopolíticas originais. Portanto, essa falta de reflexão sobre a implementação de diferentes configurações leva a uma dificuldade em considerar vários modelos que podem se sobrepor e que, além disso, evoluem de acordo com períodos e culturas macro e microscópicas. Consequentemente, essa reflexão a ser realizada não leva a considerar ir além do esquema elisiano?

\section{Conclusão}

Se a teoria de Norbert Elias é amplamente conhecida no campo das ciências sociais do esporte, sua utilização parece ser bastante controversa. De fato, muitas vezes seu uso é parcial, e os estudos falham pela falta de análise mais detalhada dos conceitos e noções formulados pelo sociólogo alemão e por seus continuadores, seja no campo da história ou na sociologia do esporte. É certo que essas dificuldades se devem em grande parte a lacunas conceituais. Parece também que a utilização de sua teoria não é necessariamente bem percebida em sua distinção entre, por um lado, o objeto a ser explicado e, por outro, o que explica. Essa ambiguidade é ainda mais evidente no campo do esporte, uma vez que é frequentemente considerado como um meio ideal para integrar e controlar a violência. Sempre na esperança de melhorar as relações sociais. Somente uma análise epistemológica e sócio-histórica bem conduzida pode medir e discutir os fundamentos e limites da teoria do processo civilizador. Dentro desta ótica, o campo das ciências sociais do esporte é interessante para fazê-los emergir devido ao seu trabalho relativamente circunscrito.

Assim, o conceito de configuração merece ser repensado em função das formas ou dos sistemas de "poder" que organizam o campo do esporte ${ }^{8}$. No entanto, à medida que este último evolui e se transforma no percurso histórico, é necessário precisar claramente o objeto estudado para não projetar uma imagem reificada (em geral, o esporte moderno de competição com toda sua institucionalidade e ética) na pesquisa. Esse pensamento determinista é forte no campo das ciências sociais do esporte, que é tradicionalmente ancorado e afirmado como uma verdade pelo movimento esportivo em geral. Isso resulta em uma não reflexão sobre o conceito de violência, porque supõe desafiar muitas ideias específicas e, em particular, a de que a violência seria mensurável apenas por critérios objetivos, principalmente quando ela estiver situada em um contexto ou configuração bastante determinada. Seria necessário repensar a noção de violência em todas as suas formas, incluindo simbólicas, que Norbert Elias, em última análise, pouco considerou (WIEVIORKA, 2000; BODIN; ROBÈNE, 2014).

Consequentemente, reflexões teóricas e estudos complementares são necessários, desde que os limites e determinantes de cada fator e categoria de análise utilizados sejam claramente discernidos (variável explicativa e variável a ser explicada). Por fim, refletir sobre a teoria do processo civilizador no esporte à luz de trabalhos empíricos recentes (históricos e sociológicos)

8 Como exemplo pode-se mencionar o trabalho realizado sobre a política esportiva de Jean Minjoz na cidade de Besançon (LOUDCHER, 2015). 
abre novos caminhos teóricos e pragmáticos que "superam" a obra do sociólogo alemão, mas que acabam também testemunhando a fecundidade de seu modelo teórico.

\section{Referências}

ARNAUD, Pierre. Une histoire du sport. Paris : La Documentation française, 1995.

ARNAUD, Pierre. RIORDAN, James. Sports et relations internationales (1900-1941): Les démocraties face au fascisme et au nazisme. Paris : L'Harmattan, 1998.

BECK, Ulrich. La société du risque: Sur la voie d'une autre modernité. Paris : Aubier, 2001.

BODIN, Dominique; ROBÈNE, Luc. Sport and civilisation: Violence mastered. From the lack of a definition for violence to the illusory pacifying role of modern sports. The International Journal of the History of Sport, v. 31, n. 16, p. 1939-1955, 2014.

BRAILSFORD, Dennis. A Taste for Diversions: Sport in Georgian England. Cambridge : Lutterworth Press, 1999.

CHANDLER, Timothy JL. Games at Oxbridge and the public schools, 1830-80: the diffusion of an innovation. The International Journal of the History of Sport, v. 8, n. 2, p. 171-204, 1991.

CHARTIER, Roger. Pour un usage libre et respectueux de Norbert Elias', Vingtième Siècle. Revue d'histoire, 106.2 (2010) p. 37-52.

CHARTIER, Roger; VIGARELLO, Georges. Les trajectoires du sport. Le débat, v. 19, p. 35-58, 1982.

COLLINS, Tony. History, theory and the 'civilizing process'. Sport in History, v. 25, n. 2, p. 289-306, 2005.

COLLINS, Tony. Early Football and the Emergence of Modern Soccer, c. 1840-1880. The International Journal of the History of Sport, v. 32, n. 9, p. 1127-1142, 2015.

CORBIN, Alain. L'avènement des loisirs: 1850-1960. Paris: Flammarion, 1995.

COTTRET, Bernard. Histoire d'Angleterre, XVIe-XVIIIe siècle. Paris: Presses universitaires de France, 1996.

CRONIN, Mike ; HOLT, Richard. The Globalisation of Sport, History Studies, v. 53, n.7, p. 26-33, 2003.

DAY, Dave; CARPENTER, Tegan. A history of sports coaching in Britain: Overcoming amateurism. London: 
Routledge, 2015.

DÉCHAUX, Jean-Hughes. Norbert Elias et Pierre Bourdieu: deux analyses conceptuelles comparées. Archives européennes de sociologie, v.31, n.2, p.364-385, 1993.

DÉCHAUX, Jean-Hugues. Sur le concept de configuration: quelques failles dans la sociologie de Norbert Elias. Cahiers internationaux de sociologie, v.99, p. 293-313, 1995.

DEFRANCE, Jacques. Esquisse d'une histoire sociale de la gymnastique (1760-1870). Actes de la recherche en sciences sociales, v. 2, n. 6, p. 22-46, 1976.

DEFRANCE, Jacques. L'autonomisation du champ sportif. 1890-1970. Sociologie et sociétés, v. 27, n. 1, p. 1531, 1995.

DELUERMOZ, Quentin; SINGARAVÉLOU, Pierre. Pour une histoire des possibles: Analyses contrefactuelles et futurs non advenus: Analyses contrefactuelles et futurs non advenus. Paris : Le Seuil, 2016.

DUCRET, André. Le concept de ‘configuration' et ses implications empiriques: Elias avec et contre Weber". Sociologies, p.1-13, 2011.

DUERR, Hans-Peter. Nudité et pudeur: le mythe du processus de civilisation. Paris: Ed M.S.H., 1998.

DUNNING, Eric. Sport matters: Sociological studies of sport, violence, and civilization. London: Routledge, 1999.

DUNNING, Eric; MAGUIRE, Joseph. Rôle des processus sociaux dans le sport, les relations entre les sexes et le contrôle de la violence. Sociologie et sociétés, v. 27, n. 1, p. 117-137, 1995.

DUNNING, Eric; SHEARD, Kenneth. Barbarians, gentlemen and players: A sociological study of the development of rugby football. London: Routledge, 2004.

EHRENBERG, Alain. Les significations et les dimensions sociales du sport : sport égalité, individualisme, Sport et société, Cahiers français, v.32, n. 2, p. 43-48, 2004.

EICHBERG Henning. Der Beginn des modernen Leistens. Terminologische Verschiebungen in der Bewertung von Leibesubüngen um 1800. Sportwissenschaft, v. 4, p.21-48, 1974.

EICHBERG Henning. Body Culture. New York: Routledge 1997.

ELIAS, Norbert. La Civilisation des mœurs. Paris: Calmann-Lévy, 1973. 
ELIAS, Norbert. La Société de cour. Paris: Calmann-Lévy, 1974).

NORBERT, Elias. La dynamique de l’Occident. Paris : Calmann-Lévy, 1975.

ELIAS, Norbert. Sport et violence. Actes de la recherche en sciences sociales, v. 2, n. 6, p. 2-21, 1976.

ELIAS, Norbert. What is sociology? Londres: Hutchinson, 1978

ELIAS, Norbert. Interview biographique : Norbert Elias par lui-même. Paris: Éditions Fayard, 1991.

ELIAS, Elias; DUNNING, Eric. Sport et civilisation. Paris : Fayard, 1984.

ELIAS, Elias; DUNNING, Eric. Quest for Excitement: Sport and Leisure in the Civilizing Process. Oxford: Basil Blackwell, 1986.

ELIAS, Elias; DUNNING, Eric. Sport et civilisation: La violence Maîtrisée. Paris: Fayard, 1994.

ELIAS, Norbert ; SCOTSON, John L. Logiques de l'exclusion: Enquête sociologique au cœur d'une communauté. Paris: Éditions Fayard, 1997.

FAURE, Jean-Michel; SUAUD, Charles. La raison des sports: Sociologie d'une pratique singulière et universelle. Paris : Raisons d'agir, 2015.

FORD, John. Cricket: A Social History, 1700-1835. Newton Abbot : David and Charles, 1972.

FOUCAULT, Michel. Surveiller et punir. Paris: Gallimard, 1975.

GOULSTONE, John. The First Running Grounds 1835-1870, Sports History, v. 8, p. 19-24, 1986.

GOULSTONE, John. The working-class origins of modern football. The International Journal of the History of Sport, v. 17, n. 1, p. 135-143, 2000.

GUTTMANN, Allen. From ritual to record: The nature of modern sports. New York : Columbia University Press, 1978.

GUTTMANN, Allen. Recent works in European Sport History. Journal of Sport History, v.10, n.1, p. 35-49, 1982.

HARVEY, Jean. Discussion pour une approche plurielle de la mondialisation du sport. OHL, Fabien (org.). Sociologie du sport, perspectives internationales et mondialisation. Paris: Presses Universitaires de France, 
2006. p.43-57.

HEINICH, Nathalie. La Sociologie de Norbert Elias. Paris: La découverte, 1997.

HOBSBAWM, Eric; RANGER, Terence (Ed.). The invention of tradition. Cambridge University Press, 2012.

HOLT, Richard. Sport and the British: a modern history. Oxford University Press, 1989.

JOLY, Marc. Devenir Norbert Elias. Histoire croisée d'un processus de reconnaissance scientifique: la réception française. Paris: Fayard, 2012.

LOUDCHER, Jean-François. La France au centre de la modernité sportive. In : TÉTART, Phlippe (org.), Histoire du sport en France, Du Second Empire au Régime de Vichy. Vuibert-Musée National du Sport, 2007, p.107129.

LOUDCHER, Jean-François. À propos de la traduction française du livre de Allen Guttmann, From Ritual to Record: the Nature of Modern Sports. Staps, n. 2, p. 39-51, 2008.

LOUDCHER, Jean-François. Le "système" Minjoz au prisme de la politique sportive municipale de Besançon (1945-1959): un gouvernement de compromis particulier. French Politics, Culture \& Society, v. 33, n. 3, p. $24-$ 46, 2015.

LOUDCHER, Jean-François. Spécificités socio-politiques et culturelles de la destinée d'un jeu de balle traditionnel rural français: la non-sportivisation de la soule (choule). Sport History Review, v. 1, n. aop, p. 1-20, 2019.

LOUDCHER, Jean-François; DAY, Dave. The International Boxing Union (1913-1946): a European sports and/ or political failure?. The International Journal of the History of Sport, v. 30, n. 17, p. 2016-2030, 2013.

LOUDCHER, Jean-François ; Monnin, Eri. Le Comité National des Sports : Un nouveau modèle de gouvernance (1901-1925)?, Olympika, XXII, p. 71-91, 2013.

LOUDCHER, Jean-François; VIVIER, Christian ; GOUNET, André. French Sports Historiography : Institutional Aspects. Stadion, v. 37, p.7-21, 2001.

MAGUIRE, Joseph. Sociologie des configurations et mondialisation du sport: thématiques, questions et objets. In : OHL, Fabien (dir.) Sociologie du sport, perspectives internationales et mondialisation. Paris, Presses Universitaires de France, 2006, p. 37-58.

MANDELL, Richard D. The invention of the sports record. Stadion, v. 2, n. 2, p. 250-264, 1976. 
PARLEBAS, Pierre. Une discipline qui prend son essor. L’Année sociologique, v. 52, n. 2, p. 239-265, 2002.

PERKIN, Harold. The origins of modern English society. London: Routledge, 2002.

POCIELLO, Christian. Les cultures sportives: pratiques, représentations et mythes sportifs. Paris: Presses Universitaires de France, 1995.

POUSSOU, Jean-Claude. La Terre et les paysans en France et en Grande-Bretagne aux XVIIe et XVIIIe siècles. Grenoble : C.N.E.D.-S.E.D.E.S, 1999.

QUÉVAL, Isabelle. S’accomplir ou se dépasser. Paris: Gallimard, 2004.

ROSANVALLON, Pierre. La démocratie inachevée. Paris: Gallimard, 2000.

STONEHENGE, John. British rural sports; comprising shooting, hunting, coursing, fishing, hawking, racing, boating and pedestrianism, with all Rural Games and Amusements. London: F. Warne and $\mathrm{C}^{\circ}, 1875$.

TERRET, Thierry. Histoire du Sport. Paris: Presses Universitaires de France, 2016.

TRAVERT, Maxime. Le «football de pied d'immeuble»: Une pratique singulière au cœur d'une cité populaire. Ethnologie française, XXVII, n.2, p. 188-196, 1997.

ULMANN, Jacques. De la gymnastique aux sports modernes: histoire des doctrines de l'éducation physique. Paris:Vrin, 1965.

VAMPLEW, Wray. Empiricist versus sociological history: some comments on the 'civilizing process'. Sport in History, v. 27, n. 2, p. 161-171, 2007.

VAMPLEW, Wray. Numbers and Narratives: Sport, History and Economics. London: Routledge, 2017.

WEST, Trevor. The Bold Collegians. The Development of Sport in Trinity College, Dublin. Dublin, The Lilliput Press, 1991.

WIEVIORKA, Michel. Sur la question de la violence. Tumultes, n. 15, p. 31-44, 2000.

WIGGLESWORTH, Neil. The evolution of English sport. London: Frank Cass, 1996.

VIGARELLO, Georges. Passion sport. Paris : Textuel, 2000.

VIGARELLO, Georges. Le sport est-il encore un jeu ?, Sciences Humaines, 152-3, Consulté le 03/10/2015 
http://www.scienceshumaines.com/le-sport-est-il-encore-un-jeu-entretien-avec-georges-vigarello_fr_4311.html

VIVIER, Christian; LOUDCHER, Jean-François; VIEILLE-MARCHISET, Gilles. Histoire de L'Histoire du Sport et de L'Éducation Physique en France. Sport History Review, v. 46, n. 1, p. 18-42, 2015.

RECEBIDO EM: 27/03/2020 APROVADO EM: 11/04/2020 